\title{
Comunicação
}

[Communication]

\section{Composição de fibras musculares esqueléticas de eqüinos jovens da raça Brasileiro de Hipismo}

[Composition of skeletal muscle fibers of young Brasileiro de Hipismo horse breed]

\author{
F.H.F. D'Angelis ${ }^{1}$, C.B. Martins ${ }^{2}$, M.A.G. Silva ${ }^{2}$, J.V. Oliveira $^{3}$, I.C. Boleli ${ }^{2}$, \\ J.C. Lacerda-Neto ${ }^{2}$, A. Queiroz-Neto ${ }^{2} *$ \\ ${ }^{1}$ Bolsista da FAPESP \\ ${ }^{2}$ Faculdade de Ciências Agrárias e Veterinária - UNESP \\ Via de acesso Prof. Paulo Donato Castellane, s/n \\ 14884-900 - Jaboticabal, SP \\ ${ }^{3}$ Polo Regional de Desenvolvimento Tecnológico dos Agronegócios de Alta Mogiana, Colina, SP
}

A raça Brasileiro de Hipismo $(\mathrm{BH})$ é reconhecida pelo World Breeding for Sport Horses (International..., 1998) e vem se destacando em competições hípicas nacionais e internacionais.

Diversas raças de eqüinos foram utilizadas na formação do BH. Dias et al. (2000) analisaram os dados obtidos a partir dos registros genealógicos de animais do Stud Book Brasileiro do Cavalo de Hipismo mantido pela Associação Brasileira de Criadores de Cavalo de Hipismo (Associação..., 1998) e observaram a grande influência da raça Puro Sangue Inglês (20,9\%) em sua formação.

O conhecimento da composição média dos diferentes tipos de fibras musculares em uma raça é uma ferramenta importante (embora não a única) na determinação do potencial atlético de um indivíduo. Além disso, a avaliação morfométrica periódica dos diferentes tipos de fibras musculares pode direcionar o treinamento físico dos animais para provas específicas. A espécie eqüina apresenta três tipos de fibras consideradas "puras", as fibras do tipo I, IIA e IIX, existindo também a ocorrência de dois tipos "híbridos" de fibras, a tipo C, que expressa a cadeia pesada de miosina I (CPM I) e a CPM IIA, e a tipo, IIAX-XA, que expressa as CPM IIA e IIX (Serrano e Rivero, 2000). De acordo com esses autores, a isoforma IIB não é expressa em tecido muscular eqüino. Portanto, ocorrem cinco tipos de fibras em eqüinos: I, C, IIA, IIAX$\mathrm{XA}$ e a IIX.

Ao se pesquisar a composição bioquímica e estrutural de fibras musculares esqueléticas de cavalos atletas da raça Brasileiro de Hipismo, não foram encontrados na literatura trabalhos sobre este tema. Dessa forma, objetivou-se determinar a composição estrutural de fibras musculares estriadas esqueléticas no músculo gluteus medius de cavalos jovens da raça Brasileiro de Hipismo por meio de análises histoquímicas de atividade da adenosina trifosfatase miofibrilar (m-ATPase) e nicotinamida adenina dinucleotídeo tetrazólio redutase (NADH-TR), de acordo com o sexo e a profundidade da biópsia.

Utilizaram-se 21 eqüinos, machos e fêmeas, com idade média de $2,4 \pm 0,09$ e $420 \pm 25 \mathrm{~kg}$ de peso, da raça Brasileiro de Hipismo, provenientes do Haras Pólo Regional de Desenvolvimento Tecnológico de Agronegócios da Alta Mogiana, localizado no município de Colina, estado de São Paulo. Os animais foram selecionados por não apresentarem sinais ou sintomas compatíveis com lesões músculo-esqueléticas. Todos os

Recebido em 20 de outubro de 2005

Aceito em 8 de maio de 2006

*Autor para correspondência (corresponding author)

E-mail: aqueiroz@fcav.unesp.br 
animais eram mantidos inativos em piquetes de Panicum maximum Jacq. var. maximum e Panicum maximum var. Tanzânia, suplementados com ração concentrada uma vez ao dia e recebendo sal mineralizado e água à vontade.

A biópsia muscular percutânea por agulha tipo Bergström $6,0 \mathrm{~mm}$ permitiu a retirada de fragmentos do músculo gluteus medius esquerdo nas profundidades de $20 \mathrm{~mm}$ e $60 \mathrm{~mm}$, que foram processados de acordo com procedimentos descritos por D’Angelis et al. (2005).

O potencial oxidativo das fibras musculares esqueléticas foi avaliado por meio da NADH TR (Novikoff et al., 1961) e, para investigar a velocidade de contração, utilizou-se a técnica de mATPase modificada por D'Angelis et al. (2005).

A área de secção transversal (AST) média das fibras foi calculada em $\mu \mathrm{m}^{2}$, a partir da mensuração de 100 secções transversais de cada tipo de fibra. A freqüência média de cada tipo de fibra (\%) foi obtida como porcentagem do número total de fibras, presentes por campo microscópico analisado, obtidas aleatoriamente dos cortes histológicos a partir de imagens capturadas por fotomicroscópio ${ }^{1}$ e analisadas por um programa de análise de imagem ${ }^{2}$. A área total relativa (ATR) média de cada tipo de fibra nos campos microscópicos analisados foi calculada em porcentagem (\%), de acordo com Rivero et al. (1993).

Os resultados foram analisados por meio de análise de variância, utilizando-se o PROC GLM do programa computacional SAS (User's... 2002). Utilizou-se o teste de Tukey para comparação das médias das freqüências e da ATR entre os diferentes tipos de fibras musculares, estabelecendo-se o nível de significância em 5\%. Para análise das médias das freqüência e ATR na comparação entre os sexos e os dois diferentes tipos de profundidades, utilizou-se o teste $t$ de "student" $(\mathrm{P}<0,05)$.

Os resultados da freqüência dos diferentes tipos de fibras musculares (Tab. 1) mostram que as fibras tipo IIX ocorrem com maior freqüência,

\footnotetext{
${ }^{1}$ Camedia Olympus 95-98 ME, Olympus

${ }^{2}$ Image pro Plus, Cybernetica
}

seguidas das fibras tipo IIA e, por último, as tipo I no músculo gluteus medius de cavalos $\mathrm{BH}$.

Tabela 1. Freqüência média (F; \%) de cada tipo de fibra e área total relativa (ATR) do músculo Gluteus medius de eqüinos, machos e fêmeas, da raça Brasileiro de Hipismo nas profundidades de $20 \mathrm{~mm}$ e $60 \mathrm{~mm}$

\begin{tabular}{lcccc}
\hline & & $\begin{array}{c}\text { Macho } \\
(\mathrm{n}=9)\end{array}$ & $\begin{array}{c}\text { Fêmea } \\
(\mathrm{n}=12)\end{array}$ \\
\hline & $20 \mathrm{~mm}$ & IIA & $18,9 \pm 5,7 \mathrm{a}$ & $18,7 \pm 4,2 \mathrm{a}$ \\
& & $30,3 \pm 3,5 \mathrm{~b}$ & $29,4 \pm 4,7 \mathrm{~b}$ \\
Freqüência (\%) & & IIX & $50,8 \pm 5,0 \mathrm{c}$ & $51,8 \pm 5,5 \mathrm{c}$ \\
& & I & $16,9 \pm 3,0 \mathrm{a}$ & $20,3 \pm 6,7 \mathrm{a}$ \\
& $60 \mathrm{~mm}$ & IIA & $33,9 \pm 4,7 \mathrm{~b}$ & $31,3 \pm 8,2 \mathrm{~b}$ \\
& & IIX & $49,2 \pm 3,5 \mathrm{c}$ & $49,2 \pm 9,2 \mathrm{c}$ \\
& & I & $10,8 \pm 3,5 \mathrm{a}$ & $15,4 \pm 1,2 \mathrm{a}$ \\
& $20 \mathrm{~mm}$ & IIA & $20,6 \pm 4,2 \mathrm{~b}$ & $20,0 \pm 2,3 \mathrm{~b}$ \\
ATR (\%) & & IIX & $68,7 \pm 4,3 \mathrm{c}$ & $64,6 \pm 4,1 \mathrm{c}$ \\
& & I & $11,0 \pm 2,4 \mathrm{a}$ & $11,2 \pm 12 \mathrm{a}$ \\
& $60 \mathrm{~mm}$ & IIA & $25,3 \pm 1,4 \mathrm{~b}$ & $26,0 \pm 2,1 \mathrm{~b}$ \\
& & IIX & $63,2 \pm 2,7 \mathrm{c}$ & $62,8 \pm 5,2 \mathrm{c}$ \\
\hline
\end{tabular}

Valores da freqüência e da ATR seguidas por letras distintas na coluna, dentro de cada profundidade, diferem entre si pelo teste Tukey $(\mathrm{P}<0,05)$. Não houve diferença na freqüência e na ATR na comparação entre sexos dentro da mesma profundidade e tipo de fibra muscular e na comparação entre as profundidades dentro do mesmo sexo e tipo de fibra muscular.

Não foi observada diferença significativa entre os sexos para os três tipos de fibras analisadas (Tab. 1), para freqüência e para ATR, em ambas profundidades. Da mesma forma, não se observou diferença significativa na freqüência e na ATR entre as profundidades de obtenção da amostra (Tab. 1) para os três tipos de fibras analisadas. Rivero et al. (1983), ao utilizarem cavalos Andaluz adultos, Bruce e Turek (1985), ao trabalharem com eqüinos PSI adultos, e Van den Hoven et al. (1985), ao realizarem biópsias musculares em eqüinos da raça Sela Francesa, ressaltaram que a distribuição dos diferentes tipos de fibras musculares não é homogênea dentro do músculo gluteus medius de eqüinos. Esses autores observaram que partes profundas do músculo gluteus medius possuem maiores características aeróbicas e maior porcentagem de fibra tipo I. Por outro lado, partes superficiais desse mesmo músculo apresentariam características glicolíticas e predomínio de fibras tipo IIX. Neste estudo, utilizaram-se eqüinos BH, 
raça que apresenta grande variabilidade genética em sua formação. Também foram usados animais jovens e inativos. Talvez, a formação genética dessa raça e a idade possam explicar a diferença de resultados obtidos comparados aos autores em questão.

As fibras tipo IIX apresentaram maior porcentagem no músculo gluteus medius e maior área ocupada no músculo, independentemente do sexo e da profundidade de coleta das amostras.
Os resultados indicam que o músculo gluteus medius de eqüinos jovens da raça Brasileiro de Hipismo apresenta maior metabolismo glicolítico com maior capacidade anaeróbica, o que pode ser explicado pela maior proporção de fibras do tipo IIX, que, por sua vez, parece ser decorrente da grande influência genética da raça PSI na formação do cavalo Brasileiro de Hipismo.

Palavras-chave: eqüino, Brasileiro de Hipismo, biópsia muscular, histoquímica

\section{ABSTRACT}

The aim of this study was to typify the skeletal striated fibers of the gluteus medius muscle of young Brasileiro de Hipismo (BH) horses by means of histochemical analysis with m-ATPase and NADH-TR according to the sex and the biopsy depth. It was observed that the frequency $(F ; \%)$ and the relative cross sectional area (RCSA;\%) of the fibers type IIX were greater than the fibers type IIA, which F and RCSA were greater than the fibers type I. The comparison between sex and muscles depht, showed no significant difference in F and RCSA in the three types of fibers. The results of morphometry showed that the gluteus medius muscle has greater glycolitic metabolism and anaerobic capacity because of the presence of large proportion of type IIX fibers. This may be justified by the genetic influence of Thoroughbred in the formation of Brasileiro de Hipismo breed.

Keywords: equine, Brasileiro de Hipismo breed, muscle biopsy, histochemistry

\section{REFERÊNCIAS BIBLIOGRÁFICAS}

ASSOCIAÇÃO BRASILEIRA DE CRIADORES DO CAVALO BRASILEIRO DE HIPISMO. [s.t.]. São Paulo: Fracta Produções Visuais, 1998. 46p.

BRUCE, V.; TUREK, R.J. Muscle fibre variation in the gluteus medius of the horse. Equine Vet. J., v.17, p.317-321, 1985.

D`ANGELIS, F.H.F.; FERRAZ, G.C.; BOLELI, I.C. et al. Aerobic training, but not creatine supplementation, alters the gluteus medius muscle. J. Anim. Sci., v.83, p.579-585, 2005.

DIAS, I.M.G.; BERGMANN, J.A.G.; REZENDE, A.C.C. et al. Formação e estrutura populacional do equino Brasileiro de Hipismo. Arq. Bras. Med. Vet. Zootec., v.52, p.647-654, 2000.

INTERNATIONAL breeding guide. Sires and Sport: Show jumping, dressage, eventing. Valknswaard, Drukkerij: WBFSH, 1998
NOVIKOFF, A.B.; SHIN, W.; DRUCKER, J. Mitochondrial localization of oxidation enzymes: Staining results with two tetrazolium salts. $J$. Biophys. Biochem. Cytol., v.9, p.47-61, 1961.

RIVERO, J.L.L.; SERRANO, A.L.; DIZ, A.M. et al. Changes in cross-sectional área and capillary supply of the muscle fiber population in equine gluteus medius muscle as a function of sample depth. Am. J. Vet. Res., v.54, p.32-37, 1993.

SERRANO, A.L.; RIVERO, J.L. Myosin heavy chain profile of equine gluteus medius muscle following prolonged draught-exercise training and detraining. J. Muscle Res. Cell. Motil., v.21, p.225-245, 2000.

USER'S guide: statistics. Version 5. Cary, NC: SAS Institute, 2002.

VAN DEN HOVEN, R.; BREUKINK, H.J.; MEIJER, E.F.H. et al. Variation of fiber types in the triceps brachii, longissimus dorsi, gluteus medius, and biceps femoris of horses. Am. J. Vet. Res., v.46, p.939-941, 1985. 